\title{
Morphometric analysis of acetabulum in south Indian population
}

R. Deepa ${ }^{* 1}$, Deepti Shastri ${ }^{2}$, K. Suganya ${ }^{3}$.

${ }^{* 1}$ Assistant Professor, Government Dharmapuri Medical College, Dharmapuri, Tamilnadu, India.

${ }^{2}$ Professor \& Head, Department Of Anatomy, Vinayaka Mission's Kirupananda Variyar Medical College, Salem,Tamilnadu, India.

${ }^{3}$ Assistant Professor, Government Dharmapuri Medical College, Dharmapuri, Tamilnadu, India.

\section{ABSTRACT}

Background: Hip bone, also known as the innominate bone, because it is formed by three independent elements during the sub adult life and is directly involved with child birth. The lateral surface of hip bone has a deep cup shaped acetabulum, bounded by a ridge known as rim of acetabulum articulating with the femoral head. The features of acetabulum are characteristic used for sexual dimorphism and for the design of prostheses in Total Hip Arthroplasty.

Materials and Methods: Two hundred un paired acetabular part of dry hip bones were collected for this study (50 right male,50 left male,50 right female and 50 left female) from Vinayaka Mission's Kirupananda Variyar Medical College, Salem. This study is designed to measure Acetabulum transverse diameter, Acetabulum Superoinferior diameter, Total diameter of acetabulum and Depth of acetabulum. Statistical analysis has been done in acetabulum using SPSS 21.0 software and $\mathrm{P}$ values were derived by applying unpaired student $T$ test.

Results: In the present study, mean value of left sided Acetabulum transverse diameter, Acetabulum superoinferior diameter, Total diameter of acetabulum and Depth of acetabulum among male and female shows $5.24 \& 4.9,5.99 \& 5.30,5.24 \& 4.78,2.60 \& 2.43$ respectively and all the values are higher in males than females. The mean value of right sided Acetabulum transverse diameter, Acetabulum superoinferior diameter, Total diameter of acetabulum and Depth of acetabulum among male and female shows 5.20 \& 4.71,5.26 \& $4.89,5.2 \& 4.72,2.67 \& 2.35$ respectively. All the right sided acetabular parameters are statistically significantly higher among the males as compared with females ( $P$ value $<.0001)$, because of strong skeleton and muscle mass and these parameters have minimal role in formation of birth canal.

Conclusion: The study of acetabulum may be helpful to the radiologists in diagnosing congenital hip dysplasia. For orthopaedic surgeons in planning before acetabular surgery and treatment of hip joint fractures and to understand the rarity of primary osteoarthritis. The relation between depth and diameter is of immense importance to the Orthopedicians and Radiologists.

KEY WORDS: Total Hip Arthroplasty, Acetabulum.

Corresponding Author: Dr. R. Deepa, Assistant Professor, Government Dharmapuri Medical College, Dharmapuri, Tamilnadu, India. E-Mail: drdeepasankar20@gmail.com

Access this Article online Journal Information

Quick Response code International Journal of Anatomy and Research

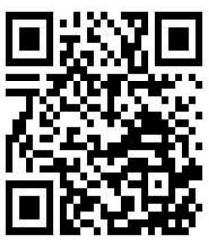

DOI: $10.16965 /$ ijar.2020.243 \section{ISSN (E) 2321-4287 | ISSN (P) 2321-8967 https://www.ijmhr.org/ijar.htm}

DOI-Prefix: https://dx.doi.org/10.16965/ijar

Article Information

Received: 01 Nov 2020

Peer Review: 01 Nov 2020

Revised: None
Accepted: 29 Dec 2020

Published (O): 30 Jan 2021

Published (P): 05 Mar 2021

\section{INTRODUCTION}

Identification of sex from the skeletal remains of an unknown individual is the most important step encountered by the forensic investigation and bio archaeologists. The study of sexual dimorphism of bones in 
human population is a matter of interest not only for anatomists but also for anthropologists. It is of great medico legal and anthropological importance. Age, sex, stature and ethnic background are the main features for biological identity. Hip bone is a large, irregularly shaped, centrally constricted bone which is expanded above and below and it is contributed by three bones. Each hip bone has ilium, ischium, and pubis which are connected by cartilage and united as one bone in adults. It is rather impossible to determine the sex of an individual from his skeletal remains unless all the bones are available, except the hip bone which is probably the only bone which is valuable as a single unit in this regard. Each group should have specific standards to optimize the accuracy of identification so that it is recognised widely and skeletal characteristics among population. The features of acetabulum are characteristic and are commonly used for sexual dimorphism.

The present study has been done with an aim to find out the sex by using various parameters of acetabulum help in determining the gender and to find out the relationship between the depth and diameter which will be useful in preparing suitable sizes of prostheses which are more functional to prevent complications like prosthetic loosening or dislocation in total hip arthroplasty [1,2]. The aim of the current study is to examine their utility in the metric determination of sex in skeletal remains of South Indian origin.

The main objective of the present study is to do the morphometry of 200 adult dry human acetabulum ( 50 right male, 50 left male, 50 right female and 50 left female) in the South Indian population to evaluate various parameters of hip bone. The parameters establish the impact of the sex factor on the morphometry of acetabulum bone and the introduction of metric method has provided accuracy and simplicity to determine the sex of skeletal remains. The measurements done on right and left side shows that there is bilateral asymmetry of acetabulum. Racial differences in Chinese, Nigerians and other populations have been compared. Not much work has been done in South Indian population, so a need was felt the for present study to be carried out.

\section{MATERIALS AND METHODS}

Two hundred unpaired dry acetabulum were collected from the Department of Anatomy, Vinayaka Mission's Kirupananda Variyar Medical College, Salem for this study. Inclusion and exclusion criteria were set prior to sample collection. Cross sectional study has been designed to record the morphometric parameters of acetabulum, to determine the gender differences and also for the design of prostheses in Total Hip Arthroplasty with acetabular parameter.

The following parameters are measured by using Vernier callipers, Measuring scale, Doctor's tape, Pencil and Digital camera

\section{- Acetabulum transverse diameter}

- Acetabulum superoinferior diameter

- Total diameter of acetabulum

- Depth of acetabulum

A total of 200 adult human acetabulum bones of the known sex and side belonging to 50 right side (male), 50 left side (male), 50 right side (female) and 50 left side (female) have been used in this study. The sex of the acetabulum was determined based on the non metrical parameters. The bones are free from pathological or congenital defects and were fully ossified adult bones.

\section{METHODS}

\section{Parameters Measured (In Cm)}

\section{Acetabulum transverse diameter. -}

Fig. 1: Maximum distance between anterior and posterior ends of acetabular cavity.

\section{Acetabulm superoinferior diameter -}

Fig. 2: Maximum distance between upper and lower margins of acetabular cavity.

3. Total diameter of acetabulum: Average of transverse and supero inferior diameter of acetabulum.

\section{Depth of Acetabulum -}

Fig. 3: Maximum vertical distance from brim of acetabulum to deepest point in acetabular cavity. 


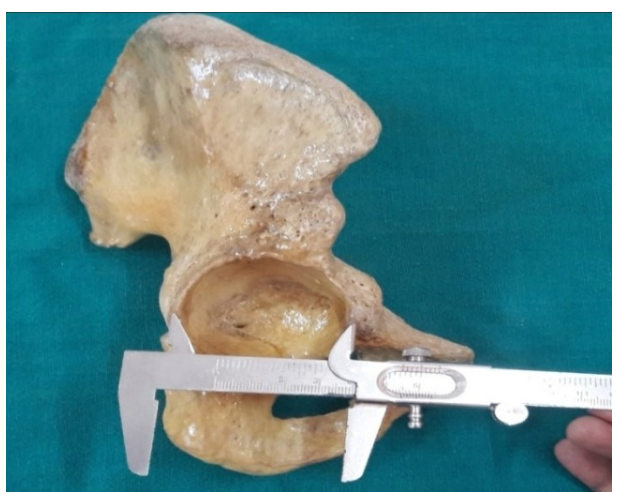

Fig. 1: Showing the measurement of the acetabulum transverse diameter.

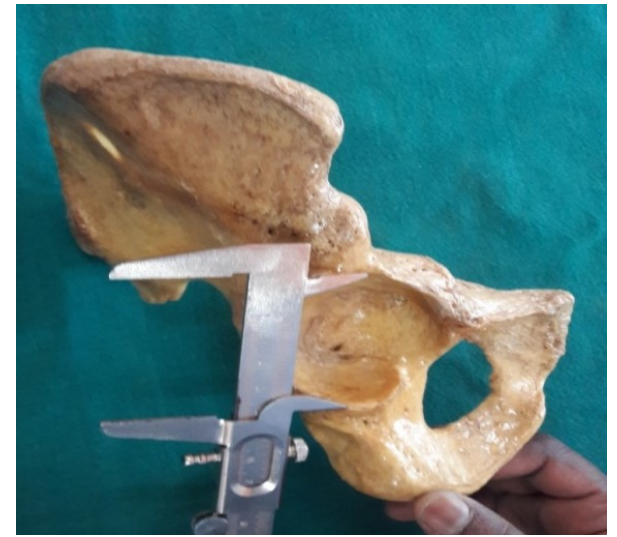

Fig. 2: Showing the measurement of acetabulum superior inferior diameter.

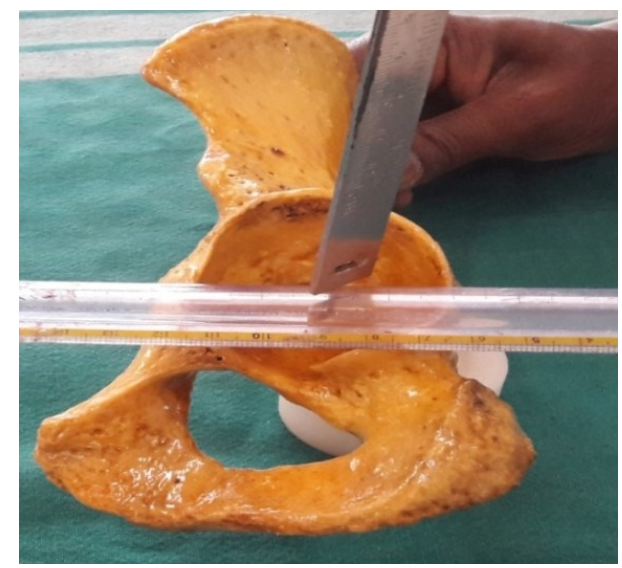

Fig. 3: Showing the measurement of depth of the acetabulum.

Statistical Analysis: Statistical analysis has been done to determine the gender differences and for the design of prostheses in acetabulum using SPSS 21.0 software

In 2016, K.Yugesh et al did a study in 60 human hip bones for morphometric analysis of acetabulum. Diameter, depth, side and notch width were taken for study. After statistical analysis the depth and diameter of acetabulum was found to be more in males than in females but notch width was more in females. No significant difference was found between left and right side of acetabulum [1].
In 2014, Ukoha U. Ukohaet al, did study in acetabulum to know the morphology and morphometry of dry adult acetabulum in Nigeria. They did the study to find out the relation between diameter and depth of acetabulum and they concluded that this relation was going to be useful for Orthopedicians to prepare suitable size of prosthesis during hip arthroplasty. Shape of anterior acetabular ridge, transverse diameter and superoinferior diameter of acetabulum were measured in 100 hip bones of unknown gender and known sides. Positive significant relationship was found between total diameter, depth and superoinferior diameter of acetabulum [2].

In 2012, Raj kumar et al studied 154 dry human hip bones to determine the relationship between width and depth of acetabulum in Indian population. The diameter of acetabulum was found to be related with depth and they found it is useful for treatment of joint fracture, hip arthroplasty and for diagnosing congenital hip dysplasia. The minimum measurements of acetabular diameter and depth were 39:13 and maximum [3] were 56:38.

In 2013, Gaurang Parmara et al studied in 100 hip bones to measure acetabular diameter and depth to find out the relation between these parameters in determining the gender. It showed significant positive correlation between depth and diameter. They concluded that curved shape of anterior acetabular ridge is the commonest presentation and it is useful for forensic medicine science [4].

In 2014, Lamvohee JMS et al in their study on Acetabulum size and bone quality for total hip replacement in 200 axial CT-Scan images from Texas, USA, noted that acetabulum are of different sizes, diameters and thickness .This information has been helpful to the orthopaedic surgeons for prosthesis [5].

In 2014, Thoudam Bedita Devi et al did a study to find out relation between acetabular depth and diameter in 100 unpaired hip bones from Pondicherry and Sikkim. They concluded that awareness of the dimensions of the acetabulum and morphology of anterior acetabular ridge is essential. This will help the surgeons and prosthetists to determine the correct size 
of the acetabular cup during Total Hip Arthroplasty [15].

\section{RESULTS}

In hip bone, parameters of acetabulum data obtained are analyzed statistically with minimum and maximum values. Mean, range, $\mathrm{Cl}$ (Confidence intervals of the mean) and standard deviation were calculated. Mean values of both sides and both sexes were also calculated using SPSS 21.0 software. $P$ values were derived by applying unpaired student T test.

Table 1: Comparison of acetabular parameters between the left side hip bones in males and females (in cms).

\begin{tabular}{lccc}
\hline \multicolumn{1}{c}{ Morphometric measurements } & $\begin{array}{c}\text { Mean among male } \\
\text { bones }(\mathrm{cms})\end{array}$ & $\begin{array}{c}\text { Mean among female } \\
\text { bones }(\mathrm{cms})\end{array}$ & P value \\
\hline $\begin{array}{l}\text { Acetabular transverse diameter } \\
\begin{array}{l}\text { Acetabular supero-inferior } \\
\text { diameter }\end{array}\end{array}$ & 5.24 & 4.91 & $<.001$ \\
$\begin{array}{l}\text { Total diameter of acetabulum } \\
\text { Depth of acetabulum }\end{array}$ & 5.99 & 5.3 & 0.003 \\
\hline
\end{tabular}

It is inferred from the Table.1 that the mean left sided Acetabular transverse diameter among male bone shows 5.24 and among female bone shows 4.91 and it is higher among males, Acetabular supero-infero diameter among male bone shows 5.99 and among female bone shows 5.30 and it is higher among males, Total diameter of acetabulum among male bone shows 5.24 and among female bone shows 4.78 and it is higher among males, Depth of acetabulum among male bone shows 2.60 and among female bone shows 2.43 and it is higher among males. All the left sided acetabular parameters are statistically significantly higher among the males as compared with females

Table 2: Comparison of acetabular parameters between the right side hip bones in males and females (in $\mathrm{cms}$ ).

\begin{tabular}{lccc}
\hline \multicolumn{1}{c}{ Morphometric measurements } & $\begin{array}{c}\text { Mean among male } \\
\text { bones }(\mathrm{cms})\end{array}$ & $\begin{array}{c}\text { Mean among female } \\
\text { bones }(\mathrm{cms})\end{array}$ & P value \\
\hline Acetabular transverse diameter & 5.2 & 4.71 & $<.0001$ \\
Acetabularsupero-infero diameter & 5.26 & 4.89 & $<.0001$ \\
Total diameter of acetabulum & 5.2 & 4.72 & $<.0001$ \\
Depth of acetabulum & 2.67 & 2.35 & $<.0001$ \\
\hline
\end{tabular}

It is inferred from the Table.2 that the mean of right sided Acetabular transverse diameter among male bone shows 5.20 and among female bone shows 4.71 and it is higher among males, Acetabular supero-infero diameter among male bone shows 5.26 and among female bone shows 4.89 and it is higher among males, the Total diameter of acetabulum among male bone shows 5.2 and among female bone shows 4.72 and it is higher among males, Depth of acetabulum among male bone shows 2.67 and among female bone shows 2.35 and it is higher among males. All the right sided acetabular parameters are statistically significantly higher among the males as compared with females ( $P$ value <.0001).

Fig. 4: Comparison of acetabular parameters in the left side hip bones in males and females.(cms)

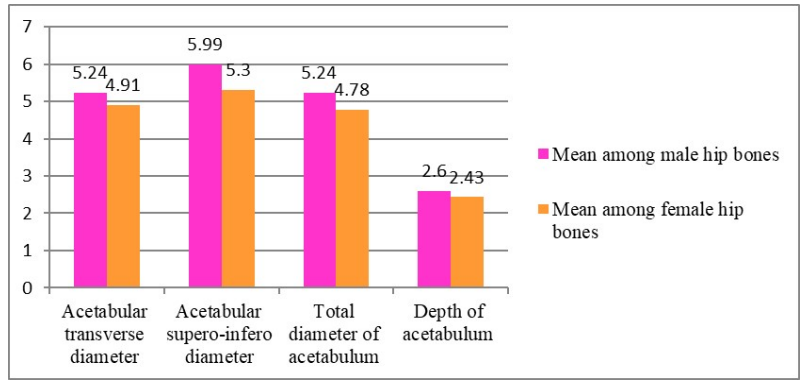

Fig. 5: Comparison of acetabular parameters in the right side hip bone in males and females (in $\mathrm{cms}$ ).

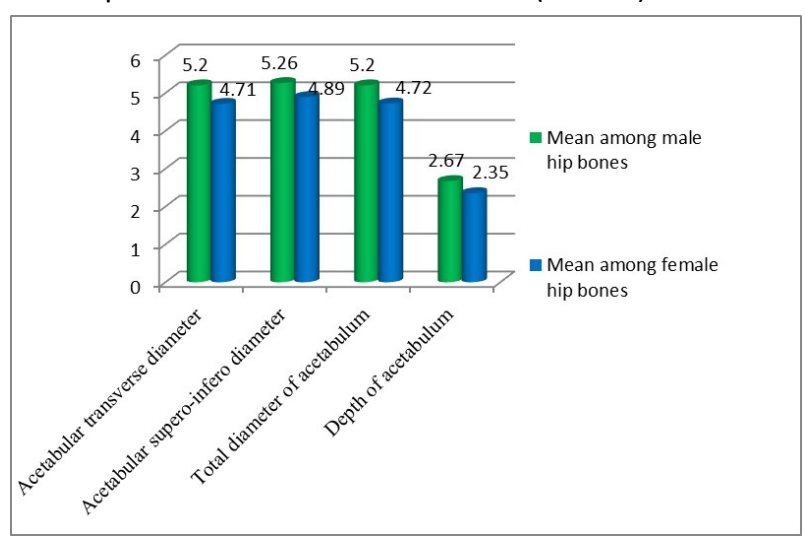

\section{DISCUSSION}

Humans are to a large extent characterized by large brains and bipedal locomotion. Because the Acetabulum is vital for locomotion, natural selection has been confronted for locomotion efficiency. The primary functions of pelvis are to bear the weight of the upper body when sitting, standing and transferring that weight from the axial skeleton to the lower appendicular skeleton.

In the present study, Four parameters were recorded in 200 dried acetabular part of hip bones with a direct method using vernier callipers and were classified into four groups according to Jaroslav Bruzek [6] method for 
visual determination of sex. The main aim of the present study is to generate data which is useful in identifying sex from skeleton and for prosthesis making for Total Hip Arthroplasty (THA). Morphology of acetabulum is important clinically for total hip arthroplasty. Prosthetic manufacturers can use this data in their production to generate sizes to fit males and females individually. Various diameter and depth of acetabulum parameters are essential for orthopaedic surgeons [7-9] to make suitable hip joint prostheses and the data is needed for detection of disputed sex by forensic experts [10-12].

In Acetabulum transverse diameter, mean value among male hip bone shows 5.22 and mean value among female hip bone shows 4.81 and values are higher in males and results are similar with Yugesh $K$ study $[1,2,4]$ the diameters of acetabulum were larger on left side (Table.1, Table.2) and the results are similar with Chauhan et al study [11].

In Acetabulum superoinferior diameter, mean value among male hip bone shows 5.62 and mean value among female hip bone shows 5.09 .In present study the superoinferior diameter was (insignificantly) greater than transverse diameter in females(Table.2) and it is similar that of UkohaU.Ukoha study [2].

In Total diameter of acetabulum values of males are higher (5.22) than female hip bones (4.75) and stastically significant in both sexes,minimal differences have been reported in between right and left sided male, female hip bones, and the results are similar with that of Yugesh study $[1,4,8]$.

In the present study, mean values in depth of acetabulum among male shows 2.64 and mean value among female shows 2.39 and values are higher among males than females. When comparing with both sides of acetabulum depth Right side 2.67 \& Left side 2.60 the value shows minimal differences similar to that of Yugesh study [1].

Total diameter of acetabulum and depth of acetabulum parameters are statistically significantly higher among the males than females in the present study and similar to that of Gaurang Parmara [4] and Aksu FT study. These values are essential for orthopaedic surgeons for suitable hip joint prostheses $[8,13,14]$.

\section{CONCLUSION}

The present study concludes that Acetabulum transverse diameter, Acetabulum superoinferior diameter, Total diameter of acetabulum and Depth of acetabulum are significantly higher among the males. The data from this study helps conclude that these are important for differentiation of sex in hip bones irrespective of sides and acetabular data are useful for gender specific prosthesis.This study will be useful for Anatomists, Forensic anthropologists and for preparing prosthesis with a better understanding.The findings of this study will help in detection of disputed sex.

\section{Conflicts of Interests: None}

\section{REFERENCES}

[1]. Yugesh K, Senthil Kumar. Morphometric analysis of acetabulum and its clinical correlateon in south indian population. International Journal of Applied Research.2016;2(6):1011-1014.

[2]. Ukoha U, Kosisochukwu E, Umeasalugo,Joseph I Okafor. Morphology and morphometry of dry adult acetabula in Nigeria. Rev Arg AnatClin. 2014;6(3):150-155.

[3]. Rajkumar, Anant Sachan, Kaiu Ram Meena. The Relationship between depth and diameter of human acetabulum in dry hip bone of Indian population. International Journal of Science and Research.2014Dec;3(12): 1574.

[4]. Gaurang Parmara,Srushti Rupareliab,Patelb SV. Morphology and morphometry of acetabulum.International Journal of Biological and Medical Research.2013;4(1):2924-2926.

[5]. Lamvohe JMS, Ingle P, Dowell J. Total hip replacement:Tensile stress in bone cement influenced by cement mantle thickness, acetabular size, bone quality and body mass index.Journal of computer science and technology.2014Mar;7:072-078.

[6]. JaroslavBruzek. A method for visual determination of sex, using the human hip bone. American Journal of Physical Anthropology.2002Aug; 117:157168.

[7]. Robinson JT. Early hominid posture \& locomotion. The differential development of the hominid pelvis. South African Medical Journal. 1976; 50:744748.

[8]. Bavornrit Chuckpaiwong, Jedsada Puangsaichai, Thossart Harnroongroj. A comparison of acetabular diameter using direct and indirect measurement. Sriiraj Medical Journal. 2009; 61: 2.

[9]. Schultz AH. Sex differences in the pelvis of primates. Am Journal of Physical Anthropology.1949; 7: 401424. 
[10]. Orban RS. An evaluation of the sexual dimorphism of the human innominate bone. Journal of Human Evolution.1980; 9: 601-607.

[11]. Chauhan R, Paul S, Dhaon BK. Anatomical parameters of north indian hip joints - cadaveric study. Journal of Anatomical Society of India. 2002; 51(1):39-42.

[12]. Pellico LG, Camacho FJ. Biometry of the anterior border of the human hip bone: normal values and their use in sex determination. Journal of Anatomy.1992;181: 417-22.

[13]. Aksu FT, Ceri NG, Arman C, Tetik S.M. Morphology and morphometry of the acetabulum. Journal of DEU faculty of medicine. 2006;20:143-48.
[14]. Chauhan R, Paul S, Dhaon BK. Anatomical parameters of north indian hip joints - Cadaveric study.Journal of Anatomical Society of India. 2002; 51: 39-42.

[15]. Thoudam Bedita Devi and Chandra Philip X. Acetabulum- Morphological and Morphometrical Study. Research Journal of Pharmaceutical, Biological and Chemical Sciences.2014Nov; 5(6): 793.

How to cite this article:

R. Deepa, Deepti Shastri, K. Suganya. Morphometric Analysis of Acetabulum in South Indian Population. Int J Anat Res 2021;9(1.1):7851-7856. DOI: 10.16965/ijar.2020.243 